\title{
"LESS CALCIUM - FEWER ORAL DOSES" A NEW APPROACH TO MILK FEVER PREVENTION
}

\author{
Nicolai Agger
}

NETTOVET A/S, Nyborg, Denmark

Ever since 1970, when Jönsson and Pehrson published some field trials with prophylactic treatment of parturient paresis, all preventive programs in the Northern part of Europe have consisted of 4 oral doses around calving of approximately $50 \mathrm{~g}$ calcium given either as calcium chloride or calcium propionate. This oral dosing program starts around 24 hours prior to calving, and is repeated again at calving, and around 12 and 24 hours post calving. In 1996, a new calcium chloride paste product (ReCovin Calcium, JØRGEN KRUUSE A/S, Denmark) for oral administration was developed. Some indications, however, were suggested that 4 doses of $50 \mathrm{~g}$ calcium around calving might interfere with a normal calving cow's own ability to mobilize calcium. Furthermore, it was hard for the producer to predict that a cow would calf approximately 24 hours from the first administration of $50 \mathrm{~g}$ calcium. Consequently, a new "less calcium-fewer doses" program was invented and tested in a field pharmacokinetic and pharmacodynamic study. 32 dairy herds from 32 different veterinary practices were enrolled in the study. Each herd provided 1 pair of Friesian cows (parity 3+), i.e., 1 test cow and 1 control cow per herd. Test cows received $50 \mathrm{~g}$ calcium as $180 \mathrm{~g}$ of calcium chloride in a paste formulation (ReCovin Calcium) when signs of calving began. This formulation is known to increase plasma calcium rapidly and to obtain sustained concentrations for 8-12 hours. Post calving treatments consisted of a new paste formulation with $125 \mathrm{~g}$ calcium propionate ( $25 \mathrm{~g}$ calcium) mixed with $30 \mathrm{~g}$ propylene glycol. This formulation was designed to provide both energy $(1736 \mathrm{~kJ})$ and more slowly released calcium. This formulation was given twice following calving, i.e., at 6 hours and again 18 hours p.p. Study outcomes were plasma calcium concentrations, clinical milk fever, and subclinical milk fever. Blood samples were drawn from all cows at calving, 6, 18, 36, and 60 hours p.p., and analyzed for plasma calcium concentration. All clinical cases were treated with calcium i.v. Clinical milk fever was recorded when cows were unable to rise, apathetic, and had cold extremities. Subclinical milk fever was recorded when cows had at least one plasma calcium value below 1.5 $\mathrm{mmol} / \mathrm{l}$ yet did not have clinical milk fever. $21.9 \%$ of control cows and $3.1 \%$ of test cows were diagnosed with clinical milk fever, and $44.0 \%$ of control cows and $19.4 \%$ of test cows suffered from subclinical milk fever. Reductions in clinical and subclinical milk fever cases were statistically significant $(\mathrm{p}<0.05)$. Mean plasma calcium concentration at calving for the 25 control cows with normal calving was $1.8 \mathrm{mmol} / 1$ and subsequently decreased to around $1.6 \mathrm{mmol} / \mathrm{l}$ at 6 and 18 hours p.p. From 18 hours to 60 hours p.p. plasma calcium concentration increased steadily to $2.0 \mathrm{mmol} / \mathrm{l}$, presumably due to the cow's own ability to mobilize calcium. Plasma calcium concentrations for the 31 treated cows with normal calving were about $0.2 \mathrm{mmol} / 1$ higher and ran parallel to the curve of control cows at all measurements. This finding is new compared to previous field studies, where plasma calcium curves for treated cows either ran unchanged at the same level or decreased slightly from 18-20 hours to 48-60 hours p.p. These results differ from previous field studies in which orally supplemented cows had slightly lower or unchanged calcium concentrations from 18 to 60 hours p.p. This may indicate a compromised ability of mobilizing calcium from the bones and calcium absorption from the gut due to oral dosing of $50 \mathrm{~g}$ calcium at 12 and 24 hours p.p. 